\title{
DEVELOPMENT OF A GREEN BIPROPELLANT HYDROGEN PEROXIDE THRUSTER FOR ATTITUDE CONTROL ON SATELLITES
}

\author{
A. Woschnak ${ }^{1}$, D. Krejci ${ }^{1}$, M. Schiebl ${ }^{1}$, \\ and C. Scharlemann ${ }^{2}$ \\ ${ }^{1}$ Forschungs- und Technologietransfer GmbH - Fotec \\ 2, Victor Kaplan Straße, Wiener Neustadt A-2700, Austria \\ ${ }^{2}$ University of Applied Sciences Wiener Neustadt \\ 3, Johannes Gutenberg-Straße, Wiener Neustadt A-2700, Austria
}

\begin{abstract}
This document describes the selection assessment of propellants for a 1-newton green bipropellant thruster for attitude control on satellites. The development of this thruster was conducted as a part of the project GRASP (Green Advanced Space Propellants) within the European FP7 research program. The green propellant combinations hydrogen peroxide (highly concentrated with $87.5 \%$ (wt.)) with kerosene or hydrogen peroxide $(87.5 \%$ (wt.)) with ethanol were identified as interesting candidates and were investigated in detail with the help of an experimental combustion chamber in the chemical propulsion laboratory at the Forschungsund Technologietransfer GmbH - Fotec. Based on the test results, a final selection of propellants was performed.
\end{abstract}

\section{INTRODUCTION}

Green propellants for satellite propulsion systems achieve great interest in the European space industry. In comparison to the currently used storable hydrazine-based propellants, they offer a significant reduction of toxicity and hazard levels. Increasing reservations and restrictions against production, transportation, and ground handling of toxic propellants in general have surfaced recently [1]. During the past years, a continuous reduction of acceptable threshold levels of ppm-concentrations of hydrazine vapors in typical working environments has been forced upon the relevant industries by governmental health organizations. In several publications and studies performed by the space propulsion industry and the European Space Agency, it was outlined that the handling and manipulation of toxic propellants on ground (e.g., on test benches and spacecraft prelaunch preparation facilities) are an increasing cost and time factor

This is an Open Access article distributed under the terms of the Creative Commons Attribution License 2.0, which permits unrestricted use, distribution, and reproduction in any medium, provided the original work is properly cited. 
which has to be accounted for during the planning of satellite projects. It is a common opinion that the transition to green propellants would bring a high economic benefit for the space industry for the near future - despite the fact that a new technology has to be introduced and qualified (see [2] for additional information).

Green propellants for in-space propulsion (e.g., orbital insertion and attitude control) were intensively investigated in the frame of the European FP7 project GRASP [3]. In this project, Fotec has proposed a bipropellant thruster concept which is based on the utilization of highly concentrated and stabilized hydrogen peroxide $(87.5 \%$ (wt.)) in combination with kerosene or ethanol. A thrust level of $1 \mathrm{~N}$ was defined for the performance of precise attitude control manoeuvres which require steady-state and also pulse-mode operation. For this thruster concept, a specific impulse in the range of $I_{\mathrm{sp}}=300 \mathrm{~s}$ is envisioned. With this target value, a green alternative to state-of-the-art bi-propellant thrusters which utilize the highly toxic and hazardous storable propellants MMH (monomethylhydrazine) and NTO (nitrogen tetroxide) could be provided (see $[4,5]$ for detailed information). Another important development goal is the provision of a blowdown mode capability. Satellite propulsion systems with blowdown mode architecture require thrusters that can be operated over a large range of system and combustion chamber pressures and also over a large domain of propellant mixture ratios. Furthermore, the thruster concept shall permit operation in biand monopropellant modes.

\section{BIPROPELLANT THRUSTER CONCEPT}

The main functional elements of the 1-newton bipropellant thruster concept are depicted in Fig. 1.

Elements 1 and 2 are the fluidic interfaces to the propellant feeding system for the hydrogen peroxide and the fuel (kerosene or ethanol). Elements 3 and 4 rep-

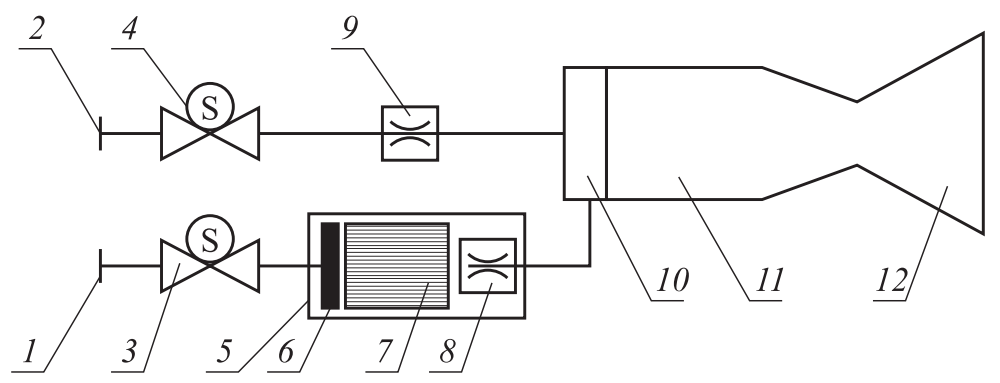

Figure 1 Green bipropellant thruster concept based on highly concentrated hydrogen peroxide 
resent the flow control valves for hydrogen peroxide and for the fuel, respectively. Element 5 depicts the decomposition chamber. Element 6 shows the hydrogen peroxide injector that is responsible for a uniform charging of the catalyst 7 where the catalytic decomposition of hydrogen peroxide occurs (see Table 3 below for further details). A porous stainless steel plate was chosen as injector. Elements 8 and 9 are the trimming devices that are necessary to adjust the flow of the decomposed $\mathrm{H}_{2} \mathrm{O}_{2}$ (consisting of steam and oxygen at theoretical decomposition temperatures of $T=690{ }^{\circ} \mathrm{C}$ ) and the fuel flow. Additionally, these devices provide the required interface conditions for the bipropellant thruster injector 10 in order to achieve optimal atomization and mixing of the propellants prior to combustion. It was anticipated that a high tangential momentum is required for an efficient combustion of the propellants in such a small-scale combustion chamber (chamber volume $V_{\text {cc }}=1450 \mathrm{~mm}^{3}$, throat diameter $D^{*}=0.7 \mathrm{~mm}$ ). Therefore, a tangential swirl injector for the decomposed hydrogen peroxide gas combined with a centric and axial liquid fuel injection is selected as injection principle. Geometric swirl numbers are in the range $0.9<\mathrm{Sg}<1.0$ (see [6] for the definition of the swirl number $\mathrm{Sg}$ ). The hydrogen peroxide flow is activated prior to the fuel flow in order to generate certain preignition pressures and temperatures in the combustion chamber 11. After the fuel is injected, the combustion of the propellant mixture will be initiated by autoignition. The combustion gases are expanded in the nozzle extension 12 .

\section{ELEGANT BREAD BOARD UNIT AND TEST FACILITY}

The decomposition chamber and the bipropellant injector were investigated in detail with experiments and with the help of theoretical methods $[7,8]$. In the further development step, it was intended to study the operation of the above described key-components in a complete thruster. An Elegant Bread Board (EBB) model of the 1-newton bipropellant thruster was established for this purpose (Fig. 2). The test data required for the evaluation of the performance during hot firing were obtained with the help of the sensors which were positioned according to Fig. 2. In order to be able to investigate the performance in steady-state conditions (with no limitations in operational time as it has to be considered in capacitive cooled concepts), a nitrogen gas cooled combustion chamber design was selected. Additionally, with the modular design of the EBB thruster unit, it was possible to test various modifications of the bipropellant injector, catalysts, and decomposition chamber configurations. As the nitrogen gas is ejected in axial direction after passing the cooling jacket, it would influence a thrust measurement. Therefore, a thrust measurement system, required for an evaluation of the specific impulse $I_{\mathrm{sp}}$ of the EBB thruster, was not included in the test setup. 


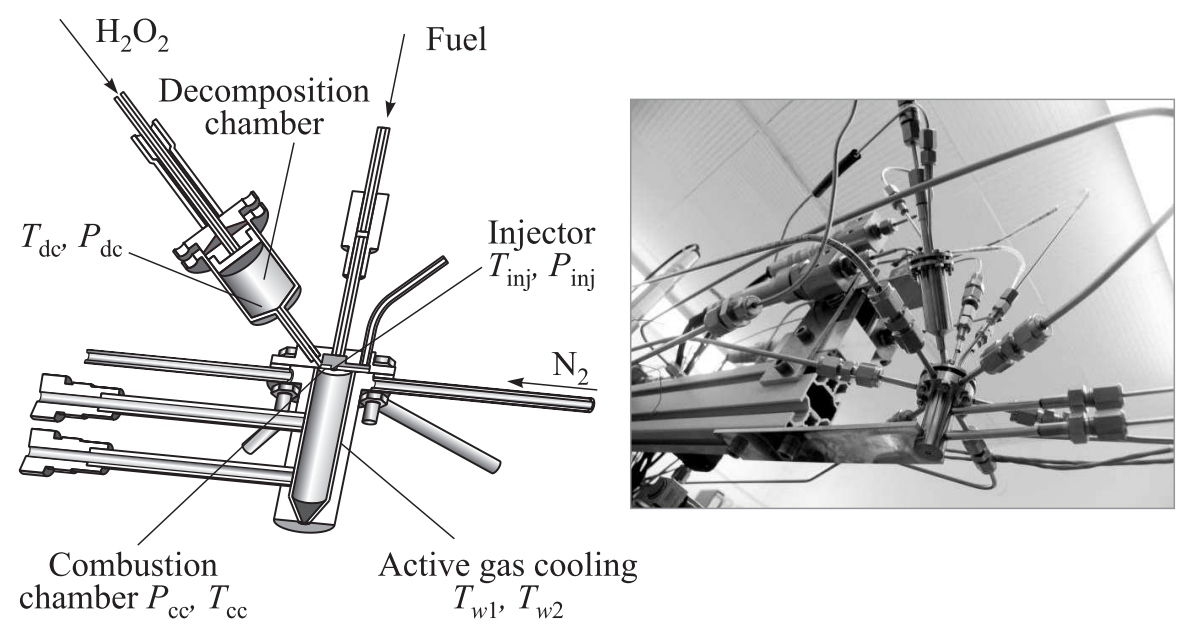

Figure 2 Elegant Bread Board thruster model

Figure 3 depicts the functional groups of the bipropellant test facility: hydrogen peroxide storage and feeding system, fuel storage and feeding system for kerosene and also for ethanol, as well as the measurement and control system.

Table 1 provides the details about the implemented measurement system and allocated sensors for the bipropellant test facility and the EBB thruster unit.

In order to be able to perform an experimental study of the thruster under operational conditions which are representative for a satellite propulsion system (note: tests have been performed at sea level), the bipropellant test bench was provided with representative functional fluidic elements and representative mass flows and system pressures (see Fig. 4 for details).

Much effort was spent analyzing the accuracies of the measurement system and sensors. Each mass flow sensor was calibrated individually with the help of a gravimetric measurement. Different constant mass flows were adjusted with this method by certain tank pressures. The emanated fluid was collected in a container during a defined period $\Delta t$ and its mass measured afterwards on a precision balance. Also, the sensor voltage signal was integrated over $\Delta t$. The division of the fluid mass and integral sensor voltage values by $\Delta t$ provides the necessary correlation between mass flow and sensor output signal. The data pairs for the Liqui-Flow sensor are summarized for kerosene in Fig. $5 a$ and for ethanol in Fig. 5b. The coriolis flowmeter (Fig. 6) was calibrated with deionized water as simulation fluid for hydrogen peroxide (the measurement principle is independent from the fluid density). A linear calibration curve was used for all mass flow sensors to approximate the data pairs. The resulting relative errors are provided in all figures. 


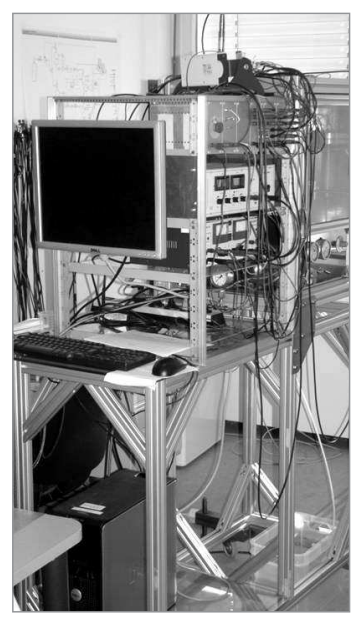

(a)

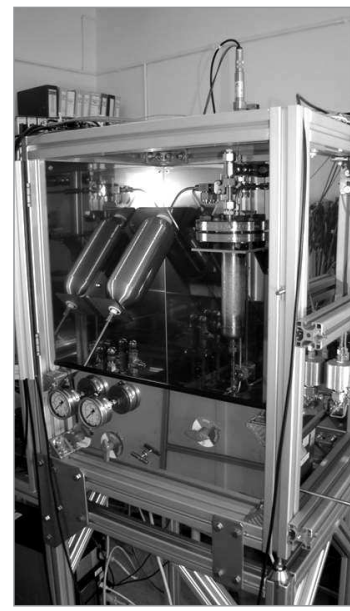

(b)

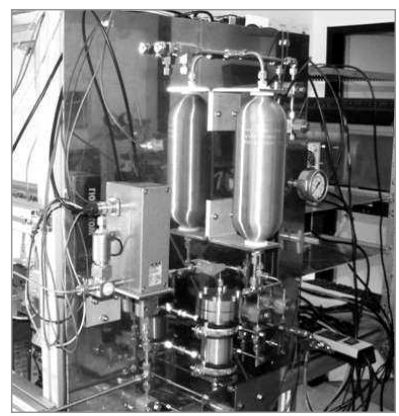

(c)

Figure 3 Bipropellant test facility: (a) control panel; (b) $\mathrm{H}_{2} \mathrm{O}_{2}$ fluidic system; and (c) ethanol/kerosene fluidic system

Table 1 Description of data acquisition system and sensors

\begin{tabular}{ll}
\hline \multicolumn{1}{c}{ System/sensors } & \multicolumn{1}{c}{ Description } \\
\hline Data acquisition & National Instruments NI cDAQ 9172 / Labview 8.6 \\
Test bench control & Software controlled valve sequencing / Labview 8.6 \\
Temperature sensors & Electronic Sensor type K thermocouples \\
Pressure sensors & Keller PA-23 SY (piezo resistive pressure transmitter) \\
$\mathrm{H}_{2} \mathrm{O}_{2}$ flow measurement & Bronkhorst Coriflow M54C5I-AAD-22-K-C \\
Fuel flow measurement & Bronkhorst Liqui-Flow L2-FAD-22-0 \\
Fluid mass & Satorius precision balance CPA 3202S \\
\hline
\end{tabular}




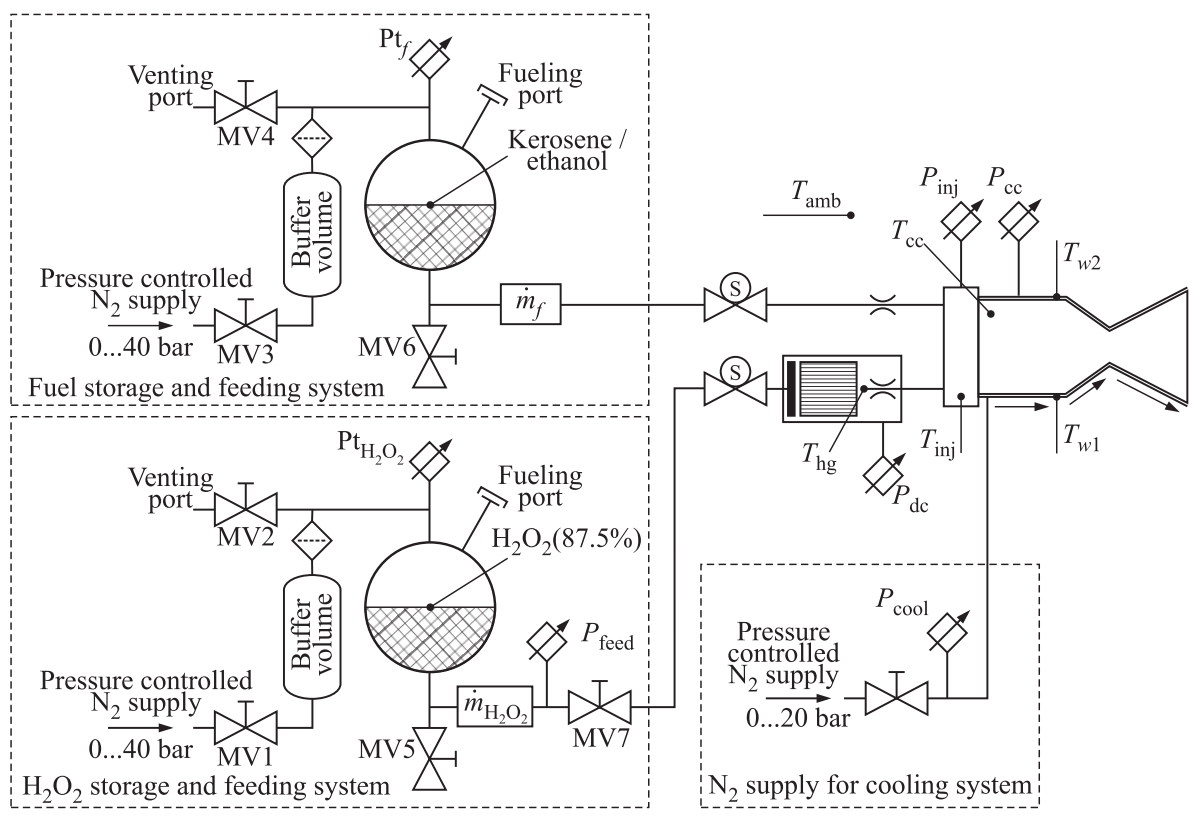

Figure 4 Flow schematics of the bipropellant test facility

Table 2 Summary measurement accuracies of implemented sensors

\begin{tabular}{llc}
\hline \multicolumn{1}{c}{ Quantity } & \multicolumn{1}{c}{ Sensor } & Measurement accuracy \\
\hline $\mathrm{H}_{2} \mathrm{O}_{2}$ mass flow & Coriflow M54C5I-AAD-22-K-C & $\pm 5 \%$ \\
Kerosene mass flow & Liquiflow L2-FAD-22-0 & $\pm 5 \%$ \\
Ethanol mass flow & Liquiflow L2-FAD-22-0 & $\pm 5 \%$ \\
Pressures & PA-23 SY & $\pm 0.5 \%$ from FS (50 bar) \\
\hline
\end{tabular}

The accuracy of the entire temperature measurement chains with type $\mathrm{K}$ thermocouples was examined with the help of a calibration furnace. In Fig. 7, the measured temperatures are compared with the adjusted furnace temperatures. The obtained percentage errors are included for information. The piezo-resistive pressure transmitters PA-23 SY were calibrated by the supplier who guarantees an error-band width of maximum $\pm 0.5 \%$ of the full-scale (FS) of the sensor.

From the preceding analysis, it can be concluded that the following maximum values of measurement errors for the envisaged ranges (see Figs. 5-7) have to be taken into account:

Characteristic velocities $c^{*}=\left(P_{\mathrm{cc}} A^{*} /(m p)\right)$ as well as combustion efficiencies are evaluated from the test data. The impact of the measurement accuracies to 


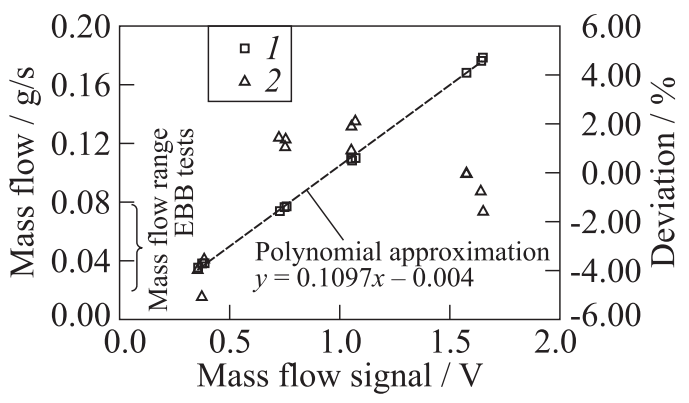

(a)

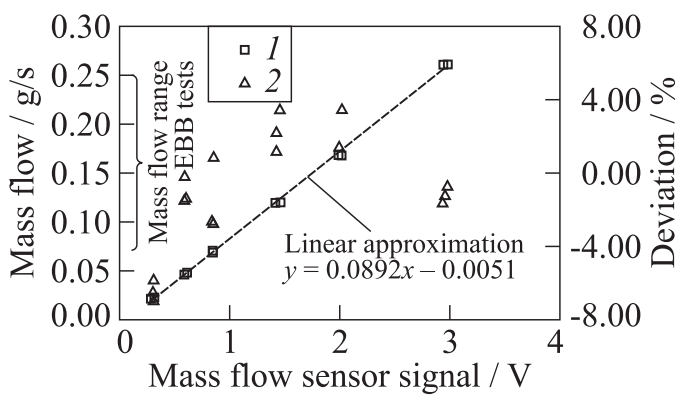

(b)

Figure 5 Sensor calibration for kerosene mass flow sensor $(a)$ and ethanol mass flow sensor $(b): 1$ - data points gravimetric measurement; and 2 - deviation

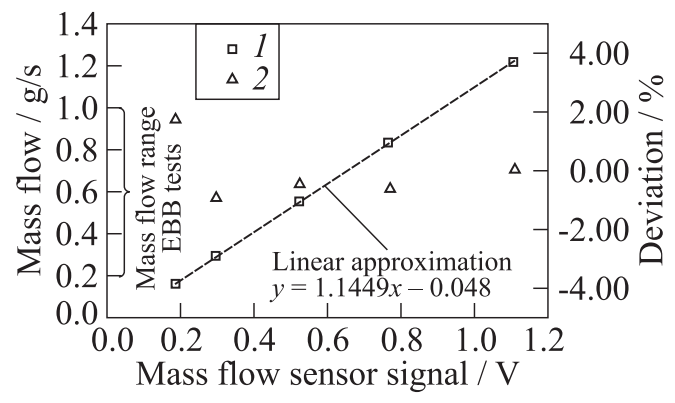

Figure 6 Sensor calibration for $\mathrm{H}_{2} \mathrm{O}_{2}$ mass flow sensor: 1 - data points gravimetric measurement; and 2 - deviation 


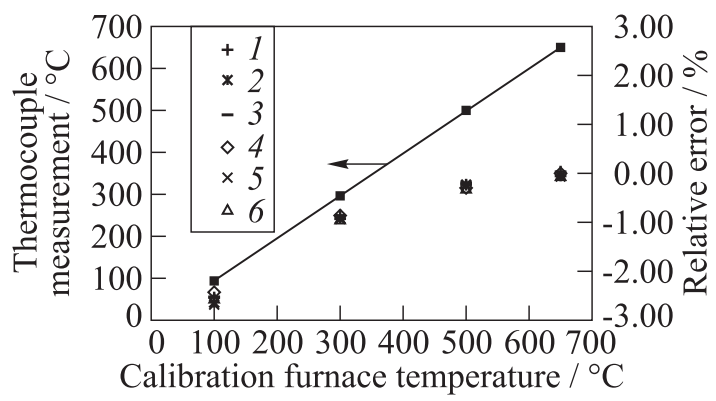

Figure 7 Sensor calibration for type K thermocouple: 1 to 6 refer to relative errors $\mathrm{TC}_{1}$ to $\mathrm{TC}_{6}$

this parameter is evaluated by propagation of independent errors and is represented by

$$
\Delta c^{*}=\sqrt{\left(\frac{\partial c^{*}}{\partial P_{\mathrm{cc}}} \Delta P_{\mathrm{cc}}\right)^{2}+\left(\frac{\partial c^{*}}{\partial \dot{m}_{\mathrm{H}_{2} \mathrm{O}_{2}}} \Delta \dot{m}_{\mathrm{H}_{2} \mathrm{O}_{2}}\right)^{2}+\left(\frac{\partial c^{*}}{\partial \dot{m}_{f}} \Delta \dot{m}_{f}\right)^{2}} .
$$

Information about achieved efficiencies will be provided below. The inaccuracies associated with the measurements are characterized by error bars.

\section{EXPERIMENTAL RESULTS}

Hot firing tests were performed with the propellant combinations $\mathrm{H}_{2} \mathrm{O}_{2} /$ kerosene and $\mathrm{H}_{2} \mathrm{O}_{2}$ /ethanol. The main purpose was the evaluation of the bipropellant injector performances under various test conditions with the two fuel candidates. One additional important point investigated carefully was the autoignition behavior of mixtures of the proposed propellants. The decomposition performances of proposed catalyst configurations were also experimentally verified.

\subsection{Elegant Bread Board Hot Firing Tests}

Figure 8 depicts the raw data obtained during a hot firing test from the sensors allocated in the EBB experimental combustion chamber. The pressure-time traces as well as the corresponding propellant mass flows for a successful ignition and hot firing are shown for $\mathrm{H}_{2} \mathrm{O}_{2}$ / kerosene (Fig. 8a) and $\mathrm{H}_{2} \mathrm{O}_{2}$ /ethanol (Fig. 8b). As can be seen from both diagrams, autoignition was detected (after 


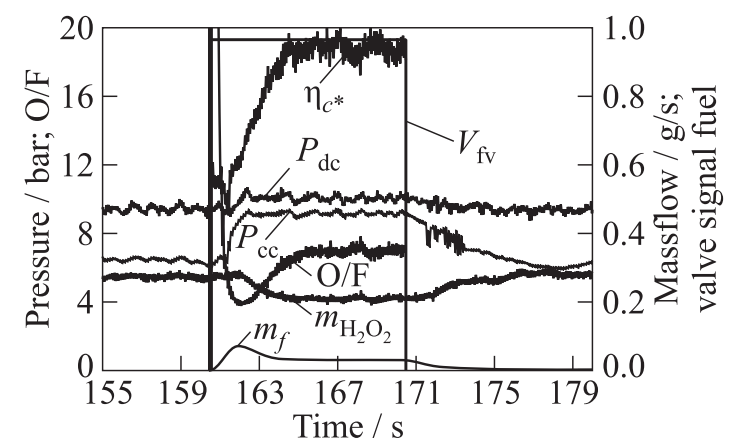

(a)

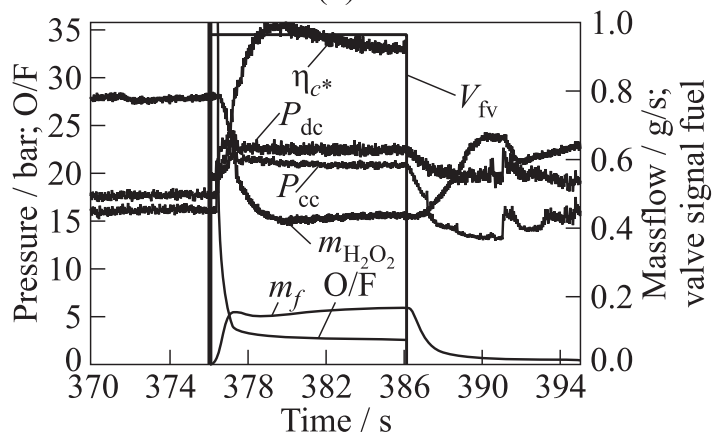

(b)

Figure 8 Hot firing test pressure and mass flow measurements: (a) $87.7 \% \mathrm{H}_{2} \mathrm{O}_{2}$ / kerosene; and (b) $87.7 \% \mathrm{H}_{2} \mathrm{O}_{2}$ /ethanol

the fuel valve open command) by a sudden rise of the combustion chamber pressure $P_{\mathrm{cc}}$ and also by the thermocouples $T_{w 1}$ and $T_{w 2}$, with which the combustion chamber wall temperatures have been monitored (see Fig. 2 for sensor positions).

Preignition pressures and temperatures were adjusted by specific tank pressure settings and preheating durations (in monopropellant mode). With this strategy, a systematic preignition pressure vs. temperature screening has been performed. Figure 9 shows the autoignition limits obtained from the EBB tests using $\mathrm{H}_{2} \mathrm{O}_{2}$ / kerosene as propellant combination. Autoignition test data from [7] are included as additional information. With the EBB experimental combustion chamber, it was also possible to investigate the ignitability of ethanol in decomposed hydrogen peroxide. Test results are shown in Fig. 10.

From Figs. 8-10, it can be clearly observed that significantly higher ignition pressures and higher ignition temperatures are required when using ethanol as fuel. The tests were performed with identical chamber dimensions but slightly different injector geometries for the two propellant combinations. 


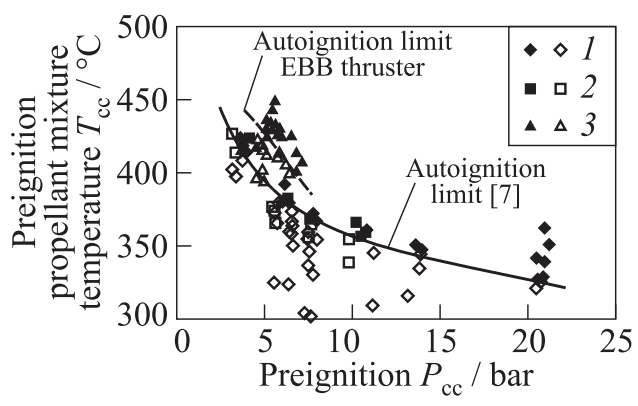

Figure 9 Evaluation of necessary autoignition conditions of $\mathrm{H}_{2} \mathrm{O}_{2} /$ kerosene: 1 $V_{c}=3156 \mathrm{~mm}^{3}[7] ; 2-1670 \mathrm{~mm}^{3}[7]$; and $3-V_{c}=1670 \mathrm{~mm}^{3}$, EBB thruster. Filled symbols refer to autoignition and empty to its absence

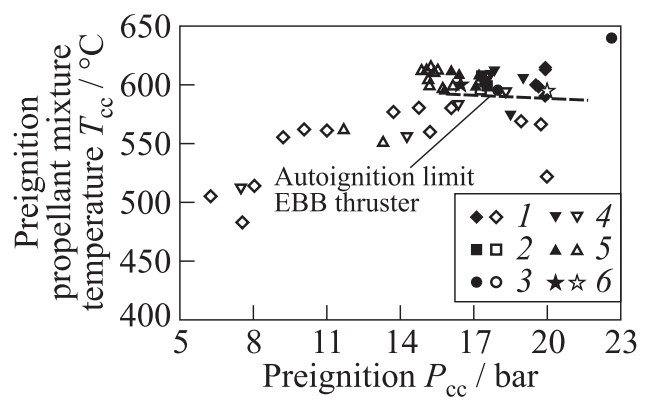

Figure 10 Evaluation of necessary autoignition conditions of $\mathrm{H}_{2} \mathrm{O}_{2}$ /ethanol (capillary, $d=0.175 \mathrm{~mm}): 1-\mathrm{O} / \mathrm{F} \sim 9 ; 2-\sim 6.5 ; 3-\sim 5.5 ; 4-\sim 4.5 ; 5-\sim 4$; and $6-\mathrm{O} / \mathrm{F} \sim 3$. Filled symbols refer to autoignition and empty to its absence

With the EBB thruster hot firing tests a systematic assessment of the steadystate performance was performed. Figures $11 a$ and $12 a$ summarize the obtained data points for $\mathrm{H}_{2} \mathrm{O}_{2}$ / kerosene and $\mathrm{H}_{2} \mathrm{O}_{2}$ /ethanol as functions of tested mixture ratios $\mathrm{O} / \mathrm{F}$ at nearly constant chamber pressures $P_{\mathrm{cc}}$. The parameter $c_{\mathrm{exp}}^{*}=\left(P_{\mathrm{cc}} A^{*} /(m p)\right)$ is the characteristic value obtained from direct measurement of combustion chamber pressure $P_{\text {cc }}$ and propellant mass flow $m_{p}$. The parameter $c_{\text {theory }}^{*}$ is the calculated characteristic velocity [9] using the theoretical decomposition temperature of hydrogen peroxide and actual mixture ratios from the tests as input.

As can be seen in Figs. $11 a$ and $12 a$, the experimental data points show a qualitative behavior of the $c^{*}$ values as functions of the mixture ratio $\mathrm{O} / \mathrm{F}$ similar to theoretical characteristic velocities, calculated with [9]. Careful treatment of the absolute values for characteristic velocities $c^{*}$ and combustion efficiencies $\eta_{c^{*}}$ 


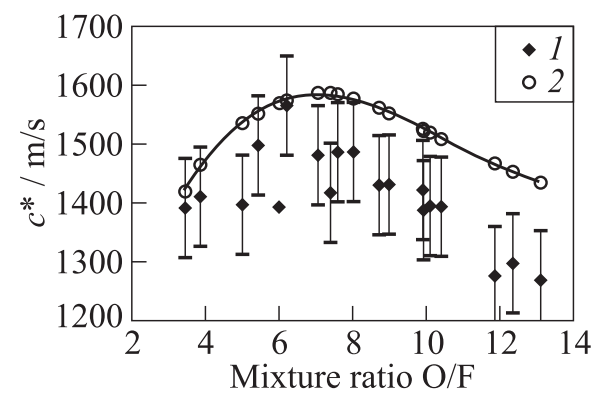

(a)

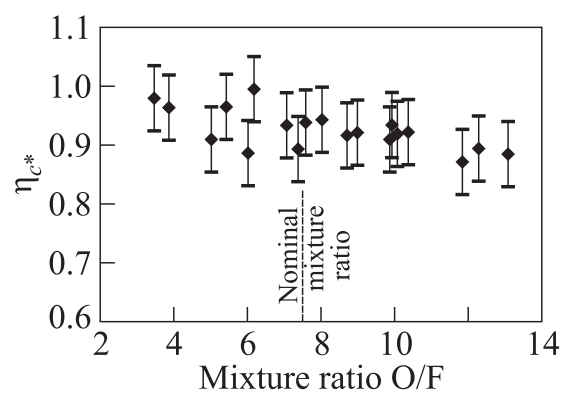

(b)

Figure 11 Thruster performance as functions of mixture ratio for $\mathrm{H}_{2} \mathrm{O}_{2}$ / kerosene $\left(P_{\mathrm{cc}}=10.7\right.$ bar $)(a) c^{*}$ evaluation $(1$ - experiment; and 2 - theory $)$; and $(b) \eta_{c^{*}}$ evaluation

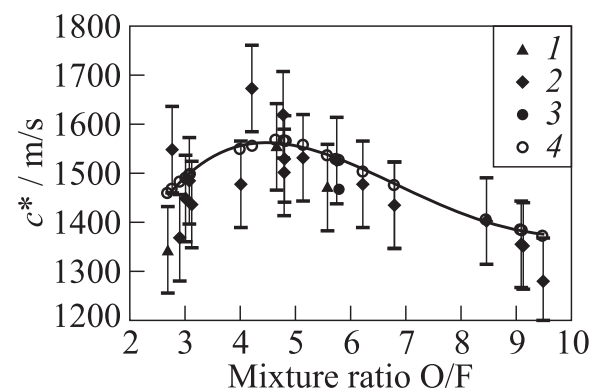

(a)

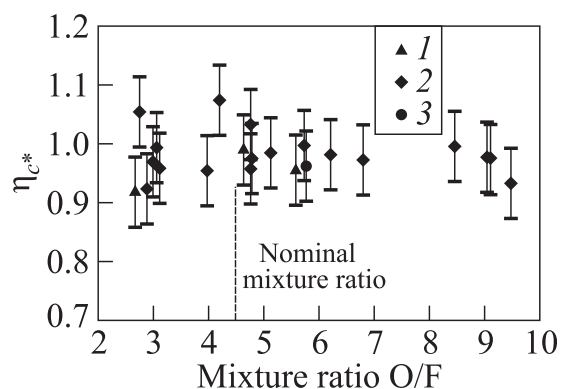

(b)

Figure 12 Thruster performance as a function of mixture ratio for $\mathrm{H}_{2} \mathrm{O}_{2}$ /ethanol: (a) $c^{*}$ evaluation; $(b) \eta_{c^{*}}$ evaluation; $1-p_{\mathrm{comb}}=20.0-22.0$ bar; $2-22.0-24.5 ; 3-$ $P_{\text {comb }}=26.2$ bar; and 4 - theory

have to be taken into account: in [10], the problematic evaluation of $c^{*}$ in the case of thrusters with small dimensions (especially, throat diameters - in our case, $D^{*}=0.7 \mathrm{~mm}$ ) is discussed. Whereas in the case of larger dimensions, the characteristic velocity $c^{*}$ can be provided with acceptable accuracies, in smaller dimensions, finite boundary layer thicknesses and, therefore, blocking effects, which significantly influence the presumed throat area $A^{*}$, need to be considered. What can be obtained as an important result from this study is the demonstration of the in-sensitiveness of combustion efficiency $\eta_{c^{*}}$ from the mixture ratio $\mathrm{O} / \mathrm{F}$. As illustrated in Figs. $11 b$ and $12 b$, no significant decay of performance was observed for both propellant combinations over the tested range. The kerosene performance data (see Fig. 11b) show a slight decrease with 


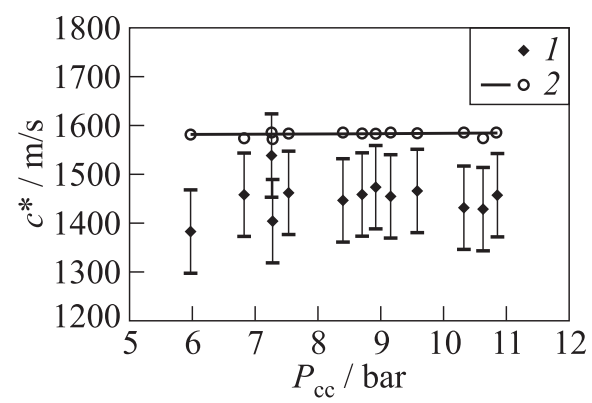

Figure 13 Thruster performance as a function of chamber pressure $\left(c^{*}\right.$ evaluation) for $\mathrm{H}_{2} \mathrm{O}_{2} /$ kerosene: 1 - experiment and 2 - theory

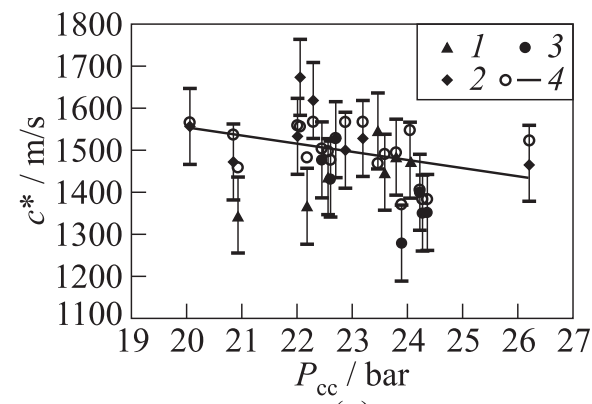

(a)

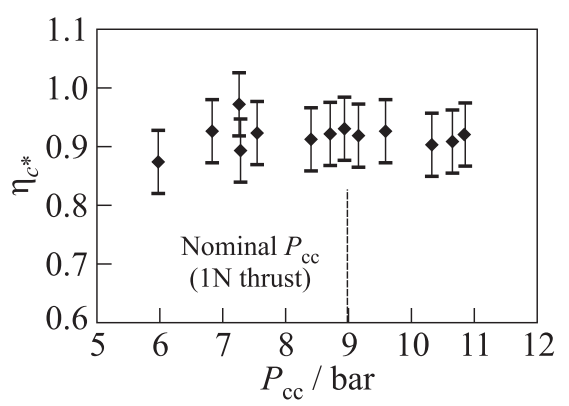

Figure 14 Thruster performance as a function of chamber pressure $\left(\eta_{c^{*}}\right.$ evaluation) for $\mathrm{H}_{2} \mathrm{O}_{2} /$ kerosene $(\mathrm{O} / \mathrm{F}=7.4)$

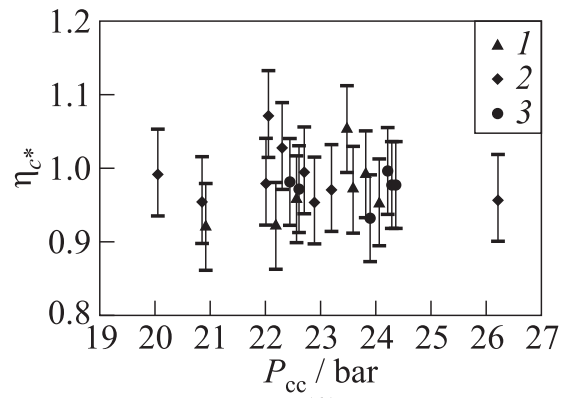

(b)

Figure 15 Thruster performance as functions of chamber pressure for $\mathrm{H}_{2} \mathrm{O}_{2}$ /ethanol: (a) $c^{*}$ evaluation; and $(b) \eta_{c^{*}}$ evaluation: $1-3-$ experiments $(1-\mathrm{O} / \mathrm{F}=2.6-4.0$; $2-4.0-6.0$; and $3-\mathrm{O} / \mathrm{F}=6.0-9.5)$; and $4-$ theory

the mixture ratio. It is indicated that the selected injection principle seems to be able to cope with large $\mathrm{O} / \mathrm{F}$ variations.

Another major aspect for the demonstration of blowdown mode capability was the evaluation of thruster performance as a function of the combustion chamber pressure $P_{\mathrm{cc}}$. The tests were performed at nearly nominal mixture ratios (nominal mixture ratios $\mathrm{O} / \mathrm{F}$, for kerosene: $\mathrm{O} / \mathrm{F}=7.4$, for ethanol: $\mathrm{O} / \mathrm{F}$ $=4.5)$

Figures 13-15 depict experimental $c^{*}$ and $\eta_{c^{*}}$ values over the tested pressure ranges for both propellant combinations. From the test results, it can be concluded that the obtained characteristic velocities and combustion efficiencies seem to be independent from the adjusted system and, therefore, chamber pres- 
sures $P_{\mathrm{cc}}$. These test results confirm the selected bipropellant injection principle for the envisioned application of the thruster.

As mentioned before, absolute values need to be interpreted very carefully (see [10]). For the next development phase, a direct thrust measurement is proposed which allows the determination of the specific impulse $I_{\mathrm{sp}}$ and which is according to [10] more precise than a $c^{*}$ evaluation (especially, for small thruster dimensions).

\subsection{Catalyst and Decomposition Chamber Tests}

The catalyst and the decomposition chamber are the key components that determine significantly the performance of the presented bipropellant thruster concept. Therefore, within the GRASP project, a considerable effort has been put

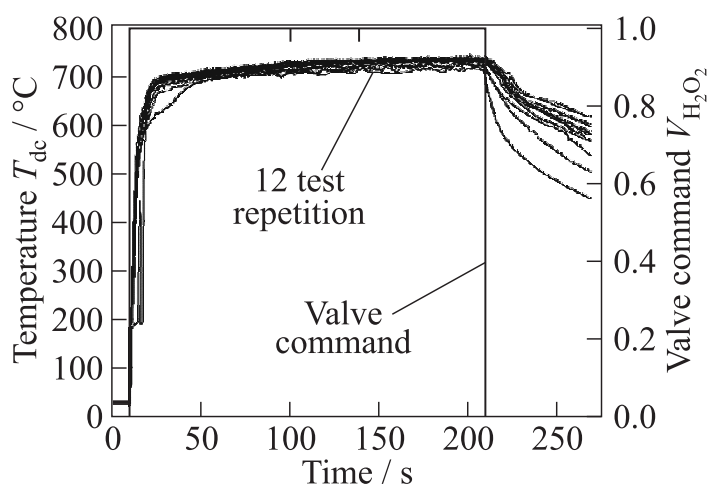

(a)

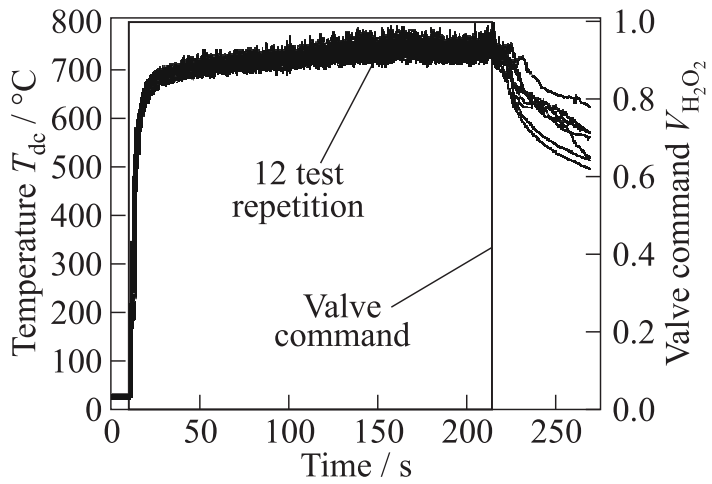

(b)

Figure 16 Catalyst and decomposition chamber tests: (a) cordierite/Pt/ washcoating $\mathrm{B}$; and $(b)$ cordierite/ $\mathrm{MnOx} /$ washcoating $\mathrm{A}$ 
Table 3 Characteristic data of catalysts

\begin{tabular}{ll}
\hline \multicolumn{1}{c}{ Parameter } & \multicolumn{1}{c}{ Characteristics } \\
\hline Substrate material & Cordierite \\
Channel density & $600 \mathrm{cpsi}$ \\
Channel cross section & Triangular \\
External diameter & $12 \mathrm{~mm}$ \\
External length & $20 \mathrm{~mm}$ \\
Catalyst bed loading tested & $2.5-5.0 \mathrm{~kg} \cdot \mathrm{m}^{2} \mathrm{~s}$ \\
Configuration \#1 & Wash coating procedure B / active phase: $\mathrm{Pt}$ \\
Configuration \#2 & Wash coating procedure A / active phase: $\mathrm{MnOx}$ \\
\hline
\end{tabular}

on catalyst development that included a systematic experimental investigation of a large number of catalyst configurations [11]. Figure 16 shows the temperaturetime traces of two final selected configurations while the EBB thruster was operated in monopropellant mode with temperature measurements of the decomposition gases immediately downstream of the catalysts (thermocouple $T_{\mathrm{dc}}$, see Fig. 2). Similar to [12], the tests indicated that cordierite-based ceramic materials are best suitable to withstand the thermomechanical loading and the chemical aggressive environment. A monolithic design of the ceramic substrate was selected with the parameters indicated in Table 3.

Both configurations provided near-ideal decomposition, lowest transition times to reach steady-state conditions, and also a high reproducibility from test to test. Platinum as active phase seems to provide a smoother decomposition than the catalyst with the manganese oxide based active phase. An important characteristic of thrusters which are based on the catalytic decomposition of hydrogen peroxide is the potential that the decomposition can be initiated without preheating the catalyst to a certain temperature level. That means the bipropellant thruster design would not necessarily require the implementation of a heating device. In comparison to hydrazine thrusters, which require heating prior the activation, a significant reduction of system complexity could be obtained.

It was interesting to know whether it is possible to achieve efficient decomposition of hydrogen peroxide also in a low-temperature environment. Figure 17 shows the temperature measurements obtained during operation of the EBB thruster in monopropellant mode at an ambient temperature $T_{\mathrm{amb}}=-0.4{ }^{\circ} \mathrm{C}$. The temperature sensor positions are described in detail in Fig. 2. The initial temperatures at the beginning of the test $(t=0 \mathrm{~s})$ indicate that the EBB structure is in near thermal equilibrium with the environment. At $t=10 \mathrm{~s}$, the hydrogen peroxide flow control valve is activated and, as can be seen from the thermocouple $T_{\mathrm{dc}}$, the catalytic decomposition starts immediately and reaches 


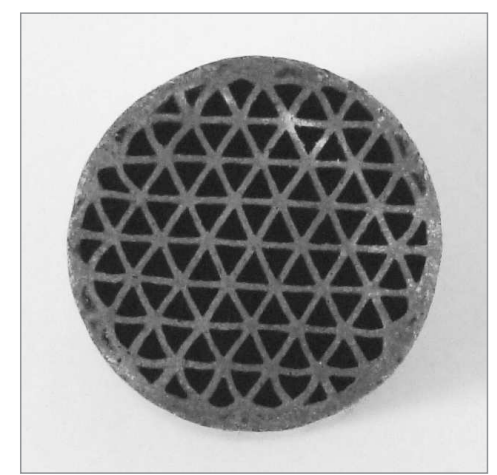

(a)

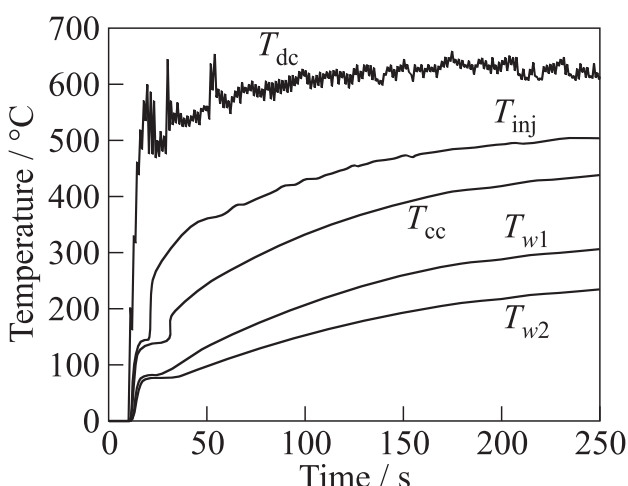

(b)

Figure 17 Monolithic catalyst $(a)$ and operation in a low-temperature environment (configuration\# 1); $T_{\mathrm{amb}}=-0.4{ }^{\circ} \mathrm{C}(b)$. Initial temperatures at $t=0 \mathrm{~s} ; T_{\mathrm{dc}}^{0}=3.3^{\circ} \mathrm{C}$; $T_{\text {inj }}^{0}=0.5{ }^{\circ} \mathrm{C} ; T_{\mathrm{cc}}^{0}=0.6{ }^{\circ} \mathrm{C} ; T_{\omega 1}^{0}=1.2{ }^{\circ} \mathrm{C}$; and $T_{\omega 2}^{0}=0.7{ }^{\circ} \mathrm{C}$

reliable and efficient decomposition at nearly ideal temperatures $\left(T=690{ }^{\circ} \mathrm{C}\right)$. It was also demonstrated that autoignition temperatures can be obtained without any heating device.

\section{PROPELLANT ASSESSMENT}

The propellant combinations hydrogen peroxide / kerosene and hydrogen peroxide/ethanol were tested with an EBB model of a 1-newton green bipropellant thruster. In the following, the assessment results for both propellant combinations are provided:

- both propellant combinations showed a reliable ignitability during the EBB thruster tests using decomposed hydrogen peroxide $(87.5 \%$ (wt.)) as oxidizer;

- a large domain of steady-state chamber pressures and mixture ratios has been successfully tested with both propellants;

- a significant reduction of the necessary preignition pressures (lowest: $P$ $=4.7$ bar; and highest: $P=22$ bar $)$ and temperatures $\left(T=330-450{ }^{\circ} \mathrm{C}\right)$ has been achieved in comparison to ethanol (lowest: $P=16$ bar; and highest: $P=20$ bar $)$ with temperatures $\left(T=580-615^{\circ} \mathrm{C}\right)$ utilizing kerosene as fuel component; 
- with the selection of kerosene, a larger margin between necessary preignition temperatures and theoretical decomposition temperatures is provided (especially if the catalyst loses performance with operational time);

- due to the fact that lower preignition temperatures are necessary for hydrogen peroxide with kerosene, also less time delays are expected during startup to reach autoignition conditions;

- due to the lower required minimum preignition pressures for hydrogen peroxide/kerosene, the envisioned steady-state thrust level of $1 \mathrm{~N}$ can be obtained at lower combustion chamber pressures. This has the advantage of a significant reduction of the thermal loading of the chamber wall structure. Note that the pressure dependency of the hot gas side heat transfer coefficients $\alpha_{h g}$ can be described by $\alpha_{h g} \sim P_{\mathrm{cc}}^{0.8}$;

- due to the fact that kerosene as fuel component lowers chamber pressures, larger blowdown ratios (BR) compared to ethanol can be realized (kerosene: $\mathrm{BR}<4.5$; and ethanol: $\mathrm{BR}<1.5)$. This would promote the implementation of the 1-newton thruster concept into satellite propulsion systems with blowdown mode architecture;

- during the general assessment of green propellants [4], it was shown that kerosene provides slightly higher performances and due to the higher mixture ratio, also a higher impulse density; and

- the increased preignition pressure levels $\left(P_{\text {ign }}>16\right.$ bar $)$ when using ethanol as propellant resulted in high values of combustion chamber pressures $\left(P_{\mathrm{cc}}>25\right.$ bar $)$ and, therefore, also system pressure levels exceeding design pressures of off-the-shelf fluidic components (tanks, flow control valves, etc.).

One important result was the determination of a catalyst configuration which provides performances which are compliant to the defined thruster requirements:

- it was demonstrated that with the monolith catalyst configurations, highly efficient and reliable catalytic decomposition of hydrogen peroxide can be achieved without the implementation of any heating devices. Lowest tested structural initial and ambient temperatures have been in the near vicinity of $T=0{ }^{\circ} \mathrm{C}$; and

- one important achievement during the evaluation of selected catalyst configurations was the demonstration of large accumulated hydrogen peroxide mass flows: $17.8 \mathrm{~kg}$ of hydrogen peroxide were decomposed with one catalyst. In comparison with the achievements of already space qualified thrusters - with the same thrust level and which rely on the operation of catalytic reactors - this represents $75 \%$ of nominal values of the ECAPS 
1-newton thruster [13] and $35 \%$ of the EADS CHT1 thruster [14]. In total, 140 cold starts and an operational time of more than $8 \mathrm{~h}$ have been accumulated.

With this sum of arguments, it was decided to use the propellant combination: hydrogen peroxide/kerosene and the currently available catalyst design for the next development phase of the 1-newton bipropellant thruster within GRASP.

\section{CONCLUDING REMARKS}

Within the FP7 project GRASP, a 1-newton bipropellant thruster for attitude control on satellites was developed that is based on the utilization of the green propellant combinations $\mathrm{H}_{2} \mathrm{O}_{2}(87.5 \%$ (wt.)) and a hydrocarbon fuel. Propellant assessment studies have indicated that kerosene and ethanol could be suitable candidates. It was possible to perform a final propellant selection assessment, using an EBB model of the proposed thruster concept. A systematic experimental investigation of autoignition and steady-state operation of the thruster clearly showed a performance advantage when using kerosene as fuel. The propellant combination $\mathrm{H}_{2} \mathrm{O}_{2}$ / kerosene offered best performances with respect to defined thruster requirements and envisioned development targets.

Another important technical aspect that was investigated carefully in the presented work was the catalytic decomposition of hydrogen peroxide. Within the GRASP project, a large number of catalyst configurations were tested. Monolithic catalysts with cordierite as substrate material and platinum or $\mathrm{MnOx}$ as active phases have been identified to be most promising. With the EBB thruster tests, the selection has been further verified and finally confirmed.

In the working plan of the GRASP project, the design and testing of an advanced development model thruster will be the next step. Maximum flexibility, maximum access of sensors as well as an active cooling system (which is not flight representative) were realized with the EBB thruster unit. This resulted in high thermal masses and, therefore, large transient times necessary to reach steadystate bipropellant operation. Therefore, one major development goal will be the implementation of flight representative chamber and nozzle materials and also cooling technology. The design and development process will be focused on structural and thermal optimization.

\section{REFERENCES}

1. Schmidt, E. W., and E. J. Wucherer. 2004. Hydrazines vs. non-toxic propellants where do we stand now? 2nd Conference (International) on Green Propellants for Space Propulsion (ESA SP-557) Proceedings. 
2. Bombelli, V., D. Simon, T. Marée, and J.L. Moerel. 2003. Economic benefits of the use of non-toxic mono-propellants for space craft applications. AIAA Paper No. 2003-4783.

3. GRASP (Green Advanced Space Propulsion). European FP7 Research Program. https://www.grasp-fp7.eu/.

4. Scharlemann, C. 2009. Global assessment of suitability and applicability. 3rd European Conference on Aerospace Sciences (EUCASS) Proceedings. Paris.

5. Scharlemann, C. 2011. Experimental verification of green propellant candidates an overview of GRASP activities. 4th European Conference on Aerospace Sciences (EUCASS). St. Petersburg.

6. Valera-Medina, A., N. Syred, and A. Griffiths. 2009. Visualisation of isothermal large coherent structures in a swirl burner. Combust. Flame 156:1723-34.

7. Schiebl, M., D. Krejci, A. Woschnak, C. Scharlemann, and F. Winter. 2010. Modeling and experimental verification of auto-ignition process for a green bi-propellant thruster. 61st Astronautical Congress (International). Prague.

8. Krejci, D., A. Woschnak, and C. Scharlemann. 2011. Hydrogen peroxide decomposition for micro propulsion: Simulation and experimental verification. AIAA Paper No. 2011-5855.

9. Gordon, S., and B. J. McBride. 1971. Computer program for calculation of complex chemical equilibrium compositions, rocket performance, incident and reflected shocks and Chapman-Jouguet detonations. NASA SP-273.

10. Powel, W. B. 1973. Simplified procedure for correlation of experimentally measured and predicted thrust chamber performances. Technical Memorandum 33-548, JPL.

11. Woschnak, A., D. Krejci, and C. Scharlemann. 2010. Investigation of catalytic decomposition of hydrogen peroxide for miniaturized chemical thrusters. Space Propulsion Conference. San Sebastian.

12. Beutien, T.R., S.D. Heister, J. J. Rusek, and S. Meyer. 2002. Cordierite-based catalytic beds for 98\% hydrogen peroxide. AIAA Paper No. 2002-3853.

13. Anflo, K., P. Thormählen, R. Möllerberg, and B. Astrand. 2008. Advancements in ADN-based mono-propellant propulsion technology. Space Propulsion Conference. Heraklion.

14. Fick, M. 1999. Low cost and low thrust monopropellant thrusters for satellites and satellite constellations. AIAA Paper No. 99-2592. 